\title{
Working with Vulnerable Primary School Aged Children and their Families
}

\author{
A review of the Australian literature on key \\ principles, issues, and community level approaches
}

\author{
Gabrielle Le Bon and Jennifer Boddy \\ Griffith University
}

\begin{abstract}
Children's health and wellbeing in Australia is adversely affected by increasing disadvantage, social exclusion, and vulnerability, with numerous studies confirming the need for an improved societal response to the needs of children and their families. This review highlights the issues facing Australian primary school aged children and their families, and it examines approaches for working with those from diverse backgrounds who have varying health needs. While there are considerable gaps in the literature, findings echo some of the preventative messages from early childhood studies which suggest that neighbourhoods and communities play a crucial role in promoting children's health, wellbeing, and social inclusion through the middle years. Research further suggests that practitioners should engage in a holistic approach to children's health and welfare and offer support across multiple domains of development, giving attention to both cultural and contextual factors. This paper will conclude with some recommendations for future research and a discussion about the implications for practice.
\end{abstract}

Keywords: primary school aged children, key issues, community interventions, programs, approaches

Children's health and wellbeing in Australia is adversely affected by increasing disadvantage, social exclusion, and vulnerability (Australian Institute of Health and Family Welfare [AIHW], 2009). The Australian Research Alliance for Children and Youth (ARACY) indicated that children in Australia fall significantly below average on many key indicators compared to other OECD countries (ARACY, 2008), and the Australian Institute of Health and Welfare (AIHW) expressed concern around a number of issues including: child homelessness, child abuse and neglect, bullying, and escalating rates of childhood obesity and diabetes (AIHW, 2009). Such issues are compounded in disadvantaged areas by limited 
parent education, family relationship problems, unemployment, and poor social connections (Hayes \& Chodkiewicz, 2003). Although researchers, educators, and policy makers recognise that the early to middle years of children's lives influence adulthood, many Australian children experience an array of disadvantages, which increases their risk of social exclusion and prevents many from participating fully in society (Daly, 2006).

Beginning school is an important transition in children's lives for social and emotional development, where they acquire literacy and numeracy skills, adopt healthy behaviours, develop their identity, establish friendships, learn how to fit in and be accepted - particularly in relation to gender, class, race, or culture - and learn how to manage conflicts (Dockett \& Perry, 2006). However, it can also increase the risk of harmful events, such as the development of chronic illness, mental and behavioural problems, poor academic achievement, and risk factors that persist into adolescence and adulthood (AIHW, 2008; Farrar, Goldfeld, \& Moore, 2007; Woodward \& Fergusson, 2000; Wright-Howie, 2007). While children who start school with a secure foundation are likely to transition smoothly into the formal school environment, those who are vulnerable, or have insecure attachments and poor boundaries, may experience stress moving into and progressing through school and develop poor coping strategies in later life. When a child enters school, developmental deficits, which may have gone unnoticed or unaddressed in a child's home, can emerge as a barrier to learning and appropriate socialisation (Brandon, Schofield, \& Trinder, 1998; Farrar et al., 2007). By the time a child reaches age five they require many of the qualities necessary for adult life such as an emotional readiness and willingness to learn, a sense of identity, an ability to relate to and communicate with other children, and an ability to use their initiative to enjoy activities that are socially acceptable (Dockett \& Perry, 2007, 2009). For many children the need to be liked and accepted as part of a group is significant and may contribute toward social inclusion in later life

This literature review explores the issues facing primary school aged children and their families and discusses community level approaches for working with children from diverse backgrounds with varying health needs. While there remain considerable gaps in the literature, research to date echoes some of the preventative messages from early childhood studies, which show that support during specific milestones in children's lives can reduce or increase a child's developmental progress. As in early childhood, neighbourhoods and communities continue to play a crucial role in children's health and wellbeing through the primary-elementary years ${ }^{1}$, and support agencies should continue to collaborate with families, schools, and communities to improve outcomes for children. Research further suggests that practitioners working with primary school aged children and their families should engage in a holistic approach to children's health and welfare, offer support across multiple domains of development, and give attention to both cultural and contextual factors.

\section{Search Methods}

This review is intended to provide a brief overview for human service, health, and social work professionals on issues with, and community level approaches to, working with children aged six to twelve and their families. It does not purport to be a detailed systematic review, but rather an introductory overview of the literature in this field of practice. As a result, a broad range of search methods was used that did not limit material to peer-reviewed articles, but instead placed value on a diverse range of sources including websites, books, and research reports. Literature was selected for review if it focused on children aged 6 to 12 years, discussed a practice intervention, and highlighted issues of concern for primary school aged children and their families. The review formed part of a study with the Northern Gold Coast Communities for Children, Australia, which aimed to identify local community 
interventions for working with primary school aged children, and thus Australian studies were prioritised. However, if relevant to the Australian context, studies from other countries were used. Articles were limited to those written in the last ten years unless they were a seminal work or had particular relevance to this topic.

A number of academic databases were searched electronically, including Informit (Humanities and Social Science Collection and the Health Collection), Proquest (Academic Research Library, Health and Medical Complete, Psychology Journals, and Social Science Journals), Australian Institute of Health and Welfare, Cambridge Journals Online, Expanded Academic (ASAP), PsychINFO, Scopus (Elsevier), Intute [Social Sciences], Informaworld, Australian Government and Politics database, SAGE Journals Online, EBSCO Host, Australian Journals Online, ISI Web of Knowledge, OECD Publications Online, and Web of Science. A range of key words was combined using Boolean logic such as school age* child*, communit*, intervention*, middle school, primary school, health, wellbeing, selfesteem, and welfare. We also searched for specific issues and fields of practice - such as health, mental health / mental illness, obesity, education, recreation / sport / exercise, indigenous / aborigin*, multicultural / culturally and linguistically diverse, school, and family - and were guided by the Australian Institute of Health and Welfare's, A Picture of Australia's Children (2009), in determining these fields. We searched the internet using Google and other search engines. The websites of the Australian Institute of Health and Welfare (AIHW), Australian Research Alliance for Children and Youth (ARACY), and the Australian Institute of Family Studies (AIFS) were particularly useful. Further key texts were identified by searching the Griffith University library database, referring to article reference lists, and consulting academics at the University who had previously conducted research with children and families.

From this initial search, it became evident that the literature largely overlooked the six to twelve year age group, focusing more on children's early years or adolescent period. Despite extensive gaps in the literature, there was an emphasis on early intervention and prevention and working in communities to promote change, particularly in addressing child homelessness, child abuse and neglect, bullying, disability, chronic illness, and mental health and wellbeing. While some literature commented on the importance of involving children in decision-making few practice or research examples of this were found.

\section{Findings}

\section{Key issues}

\section{Child homelessness}

Homeless families with children in Australia comprise approximately one quarter (26\%) of the homeless population and, in 2006, there were 12,000 homeless children under 12 years of age, an increase of ten per cent since 2001 (AIHW, 2009). Numerous factors contribute to homelessness including poverty, unemployment, a shortage of affordable accommodation, parental neglect and abuse, family violence, mental illness, and drug and alcohol problems (Nicholson, 2007). Disrupted relationships and environmental instability may negatively affect a child's physical and emotional health, and social and educational development, and delay the attainment of important developmental stages (Coker et al., 2009; Moore, NobleCar, \& McArthur, 2007; Wright-Howie, 2007). Child homelessness has been associated with a range of mental health concerns, such as depression, anxiety, eating disorders, grief, trauma, and self-harm, and it has been linked to a number of behavioural disorders including insomnia, aggression, and hyperactivity (Karim, Tischler, Gregory, \& Vostanis, 2006; Walsh, 
Milford, \& Cain, 2003; Wright-Howie, 2007). Homelessness may result in disrupted schooling, decreased socialisation, reduced access to important health care services, and a lack of identity and connection to a safe and supportive community (Kolar, 2005; WrightHowie, 2007). School aged children who experience homelessness may not be able to participate in extra-curricula activities, such as sport, excursions, and social events resulting in further social isolation and disconnection (Wright-Howie, 2007). The effects of homelessness on children may extend beyond the period of homelessness and parents may experience a range of ongoing issues which prevent them from providing adequate care and support of their children (Moore et al., 2007).

\section{Aboriginal and Torres Strait Islander children}

Aboriginal and Torres Strait Islander children continue to experience disadvantage across a broad range of health and socioeconomic indicators (AIHW, 2009). They have not seen any of the improvements in health, education, or wellbeing attributed to other Australian children and they are two to three times more likely to die than their non-indigenous counterparts (AIHW, 2008; 2009). They have poorer access to health and medical services, yet they are more like to suffer from preventable illnesses and communicable diseases (Burchill, Higgins, Ramsamy, \& Taylor, 2006). They are more likely to live in sole parent families, or with extended family, and in households in which the adults are unemployed than those living in non-Indigenous households (Daly \& Smith, 2005). They are significantly over-represented in the child welfare system being seven times more likely to enter the child protection system than other Australian children (O’Donnell, Scott, \& Stanley, 2008; Tilbury, 2009), and comprising 23.9 per cent of the Australian out-of-home care population (Higgins, Bromfield, Higgins, \& Richardson, 2006). Indigenous families are more reliant on welfare payments and parents have lower standards of education than those reported in other Australian households (Daly \& Smith, 2005). Such issues must be examined within context, recognising that Indigenous peoples have experienced extreme oppression, marginalisation, victimisation, and abuse since European colonisation - particularly in the forced separation of Aboriginal families - which has contributed to considerable socioeconomic disadvantage (Burchill et al., 2006; Silburn et al., 2006).

\section{Children with disabilities and chronic illness}

In 2003, eight per cent of Australian children had a disability and half of these children had a profound or severe core activity limitation (AIHW, 2008). Children with disabilities generally transition smoothly into school, (Chadwick \& Kemp, 2002), but as they progress they may require additional assistance in class, attend alternative classes or a special school, require frequent time away, and have problems with schoolwork or the school environment (AIHW, 2008). Further, children with disabilities are more vulnerable to abuse and neglect, both in and outside the family environment (Chenoweth, 2007), but are less likely to disclose this abuse than children who do not have a disability (Aarons \& Powell, 2003).

Australian children also experience a significant amount of chronic disease, including asthma, cancer, and Type 1 diabetes (AIHW, 2009). This can disrupt children's growth, and emotional, physical, and social development processes (Dell'Api, Rennick, \& Rosmus, 2007). It can cause difficulties in maintaining and forming friendships (Dockett, 2004) and result in physical pain and suffering and/or cognitive impairment, changes in appearance, fear of stigmatisation, extended absences from school, and restrictions on activities (Dell'Api et al., 
2007; Shiu, 2001). Parents, particularly mothers, of children with chronic illness face numerous challenges and take on multiple roles including that of medical expert, care coordinator, lobbyist, and advocate (Kratz, Uding, Trahms, Villareale, \& Kieckhefer, 2009; Ray, 2002; Vickers, Parris, \& Bailey, 2004). Further, many families experience hypervigilance, stress, anxiety and exhaustion (Ashton, 2004).

\section{Children with behavioural problems and mental illness}

Mental health concerns are increasingly apparent among Australian children, as one in every seven experience behavioural and emotional problems, resulting in cumulative personal and societal ramifications, such as poor health, impaired educational outcomes, relationship problems, and continuing emotional and behavioural problems (Sanson et al., 2002). Children's family situations - including the circumstances into which they were born, parenting practices, level of parental education and income, and family relationships - have been identified as strong predictors of mental health problems during childhood. Other factors relate to the quality of children's broader environment including peer and school networks (Davis, Sawyer, Lo, Priest, \& Wake, 2010; Higgins, 2003). Children's risk of mental health problems increases cumulatively with increased exposure to risk factors over time. If unaddressed, it can manifest in behavioural problems such as aggression, hyperactivity, and oppositional defiance; and emotional problems, which are typified in anxiety, depression, and withdrawal. It can also lead to substance abuse, criminality, and family violence in adulthood (Bayer et al., 2009).

\section{Children who are overweight}

In 2007 over one fifth of Australia's children were estimated to be overweight or obese (AIHW, 2009), with disadvantaged or minority populations, including Indigenous, South Sea Islander, and Middle Eastern communities, at most risk (O'Dea, 2008). This can cause serious health problems in the short and long term such as asthma, sleep apnoea, type 2 diabetes and, in severe cases, gallstones, liver disease, and cardiovascular problems (Batch \& Baur, 2005; Must \& Strauss, 1999; Whitlock, Williams, Gold, Smith, \& Shipman, 2005). There are numerous factors contributing to children's weight gain including economic, social, and geographical disadvantage, genetics, and cultural, economic, environmental, familial and individual behaviour patterns (O’Dea, 2008). Physical activity and nutrition are also critical factors in determining a child's body weight (Department of Health and Ageing, 2008). While 50 to 60 per cent of children aged 4 to 13 years have the recommended daily amount of fruit, only 3 per cent of 4 to 8 year olds and 2 per cent of 9 to 14 year olds consumed the recommended daily amount of vegetables (Department of Health and Ageing, 2008). In addition, the way children and adults spend their time has changed dramatically. Outside play space - and available recreational activities - has decreased. Concerns about children's safety, particularly when unsupervised in public places, have also increased. Simultaneously there has been a rise in the availability of television, computers, and video games to children, as well as labour saving devices in the home and changed parental work patterns (Sanson et al., 2002). This has contributed to a reduction in exercise for Australian children, with 25 per cent of boys and 35 per cent of girls engaging in little to no physical activity (Booth, Oakley, Chey, Bauman, \& Macaskill, 2004). Decreased levels of physical activity, along with poor nutrition, are extremely concerning and will have considerable adverse effects both short and long term for Australian children. 


\section{Children, peer relationships and bullying}

The most common form of bullying self-reported by Australian children is verbal abuse, such as name calling and teasing (Cross, 2008; Forero, McLellan, Rissel, \& Bauman, 1999). However, covert bullying-which is difficult for parents and practitioners to detect and significantly increases victim's social isolation-is becoming increasingly prevalent (Cross, 2008). A 1994 inquiry into violence in Australian schools recommended that prevention programs be implemented urgently, as bullying was a major societal problem (House of Representatives Standing Committee on Employment Education and Training, 1994). Yet bullying continues to escalate in Australia (Forero et al., 1999; Peterson \& Rigby, 1999), with an estimated one out of every six children between the ages of 8 and 18 years being victimised on a weekly basis (Rigby, 2005a).

International literature has begun focusing on the shift bullying has taken to online mediums, including instant messaging, social networking sites, email, message boards, derogatory websites about the victim, and films of abuse posted on video websites (Belsey, 2005; Fleming \& Rickwood, 2004; Smith, Mahdavi, Carvalho, \& Tippett, 2006; Wolak, Finkelhor, Mitchell, \& Ybarra, 2008). While cyberbullying mainly affects secondary school children, 7 to 10 per cent of younger children have reportedly experienced it (Cross et al., 2009). Children who are bullied may experience low academic achievement and high absenteeism, resulting in poor social and vocational outcomes (Cross et al., 2009). They may also experience a range of psychological, psychosomatic and behavioural symptoms including anxiety, depression, suicidal thinking (Rigby, 2003, 2005a), low self-esteem and self worth, headaches, abdominal pain, frequent bed wetting, sleeping difficulties, social dysfunction, and drug and alcohol use (AIHW, 2009; Forero et al., 1999).

\section{Children and abuse and neglect}

During 2007-2008, there were an estimated 7.4 child protection substantiations per 1000 children aged between 0 to 12 years (AIHW, 2009), a significantly higher rate than that of the United Kingdom and the United States (O’Donnell et al., 2008). Neglect and emotional abuse comprise the majority of substantiated child protection cases, followed by physical and sexual abuse (O’Donnell et al., 2008). During the past decade the number of children being removed from their parents has almost doubled (AIHW, 2009). This increase may be related to changes in the definitions of child abuse, increased community awareness of child maltreatment, and the introduction of mandatory reporting (McCallum, 2009; O'Donnell et al., 2008). Of concern, is the pressure that this puts on child protection systems, which may result in inappropriate statutory intervention (O’Donnell et al., 2008; Scott, 1997).

Multiple and interrelated risk factors such as poverty, mental health or child behavioural issues, physical or intellectual disability, chronic illness, substance use, domestic violence, poor family functioning, social isolation, and unsafe or uninhabitable housing directly contribute to levels of abuse and neglect (O'Donnell et al., 2008; Scott, 1997; Sidebotham \& Golding, 2001). Consequently, children who live in these environments and experience emotional or physical abuse and neglect often have poor behavioural, social, and health outcomes in the short and long term (AIHW, 2009; Grist, 2009). They may experience poor academic performance, impaired language ability, reduced social competence, sexual dysfunction, and mental health issues. Further, they may engage in compulsive and selfdestructive behaviour and have a higher likelihood of engaging in substance abuse or criminal behaviours (Grist, 2009). 


\section{Key approaches}

\section{Child homelessness}

Addressing homelessness as a priority enables practitioners to subsequently address other important accompanying issues (Coker et al., 2009; Kolar, 2005). For some children, the timely provision of this stability can be sufficient to facilitate recovery and re-connection with communities (Kolar, 2005). However, the majority of children require more intensive support that focuses on their unique needs and includes professional, consistent, and supportive workers who connect parents and children to their community and respond to family diversity appropriately (Wright-Howie, 2007). Families who attain appropriate housing and receive adequate support are often able to significantly improve the health, social, and educational outcomes of their children within a two year period (Kolar, 2005).

\section{Aboriginal and Torres Strait Islander children}

Evidence-based interventions to address the issues affecting Indigenous children are limited and an approach which considers both local and international research, combined with extensive Indigenous community engagement and genuine collaboration, is needed (Tilbury, 2009). Services and programs must be responsive to the needs and cultural beliefs of the local communities that they serve (Higgins et al., 2006; Libesman, 2004). Thus, community service organisations should develop and maintain cultural awareness and sensitivity when working with Aboriginal and Torres Strait Islander primary school aged children and their families (Higgins et al., 2006). Preventative approaches that offer intensive support to parents and extended families, as well as community development initiatives which incorporate Indigenous control and authority may be useful (Libesman, 2004), but programs must consider the evidence for their impact, strength of community support, and program feasibility (McDonald, Bailie, Rombold, Morris, \& Paterson, 2008). Aboriginal and Torres Strait Islander children and their families also require a choice of service providers as they may find it difficult to access culturally appropriate mainstream services or believe their parenting to be misunderstood by non-Indigenous workers (Abbott, 2004; Green \& Baldry, 2008).

\section{Children with disabilities and chronic illness}

Early intervention and school-based initiatives - which focus on providing a welcoming school-community response, adequate teacher support, and class-room and self-help skills preparation for children-are important (Chadwick \& Kemp, 2002). Further, approaches which encourage partnerships, good communication, and collaboration between school staff, medical staff, parents, families and communities, and are family-centred, are needed (Catroppa \& Anderson, 2008; Chadwick \& Kemp, 2002; Robson, Ziviani, \& Spina, 2005). Children with disabilities must be assessed and supported to complete their schooling to ensure they have opportunities as adults in education, employment, housing, leisure, and relationships (Drysdale \& Higgins, 2008). In addition, adequately funded, well planned, and regular respite care will help alleviate the demands and stress on families (O'Brien, 2001).

It is important for practitioners to understand the common challenges faced by parents, promote networking among empathic parents, and build partnerships with parents and their children with special health care needs (Ireys, Chernoff, DeVet, \& Kim, 2001; Kratz et al., 2009; MacKean, Thurston, \& Scott, 2005; Uding, Kieckhefer, \& Trahms, 2009). School support services for children with chronic illnesses need to be delivered in a supportive and 
caring environment, involve collaboration with the family and community, and foster positive relationships between the child and the school (Peebles-Wilkins, 2006; Shiu, 2004). The development of training programs for school staff, as well as health education for peers to enable them to recognise and respond appropriately to unhealthy signs, are important (Peebles-Wilkins, 2006; Shiu, 2001). Children with chronic illness need to maintain contact with their school and peers when they are undergoing treatment (see St Leger \& Campbell, 2008 for an evaluation of the "Back on Track" program for children with chronic illness).

\section{Children with behavioural problems and mental illness}

It is vital that human service practitioners, who are increasingly exposed to mental health issues in the community, increase their awareness of, and skills in, the identification and referral of children's mental health problems (Rivers, 2009). Primary school aged children should have access to programs which increase their capacity to manage their mental wellness and enhance protective factors by providing a caring supportive environment where strong interpersonal skills, mental wellbeing, and positive self-concept, confidence, and selfesteem are promoted (Gilmore, 1999; Sawyer et al., 2001; see Bayer et al., 2009 for a systematic review of preventive mental health interventions with children; see AskellWilliams et al., 2008; Graetz et al., 2008 for a review of KidsMatter, a national population mental health initiative). Programs should employ an integrated approach which combines an individualised child-directed component with specialised family-centred activities, including in-home help and positive parenting workshops (Bayer et al., 2009; Ryden, 2005; for Australian parenting programs with primary school aged children see, Larmar, 2008; Larmar \& Gatfield, 2005; Sanders, 1999; Stiefel \& Renner, 2004). These approaches can make a significant difference for children in need by offering advice, support, and strategies to parents experiencing stress (Ryden, 2005). Such approaches, should seek to engage all parents (Mockford \& Barlow, 2004), include fathers where possible (for information on engaging father see Bayley, Wallace, \& Choudhry, 2009), and recognise the increasing role that many grandparents play in raising children (see Woodbridge, 2008).

\section{Children who are overweight}

Programs which nurture positive attitudes toward physical activity, and encourage children to engage in it, promote ongoing health and wellbeing, thus reducing the risk of chronic disease, while improving children's self-esteem, energy levels, sleep patterns, and concentration (Hills, King, \& Armstrong, 2007; National Health and Medical Research Council [NHMRC], 2003; Okely, Booth, Hardy, Dobbins, \& Denney-Wilson, 2008; Sangster, Eccleston, \& Porter, 2008). Although it is important to promote the idea that physical activity can be undertaken at any time, not solely during competitive team sports (Sangster et al., 2008), physical activity is best undertaken in the afternoon after school, as this period determines overall physical inactivity or sedentary behaviour patterns (Sangster et al., 2008). Further, it is crucial to establish healthy eating patterns in primary school aged children. Programs will be most successful at addressing childhood obesity if they involve parents and families (Timperio, Salmon, \& Ball, 2004), incorporate a nutritional educational component (Sangster et al., 2008), and recognise the emotional issues surrounding food and weight for many parents (Booth, King, Paginini, Wilkenfield, \& Booth, 2009). Vegetable gardens, (Somerset, Ball, Flett, \& Geissman, 2005), breakfast clubs (Radcliffe et al., 2005), and multi-strategy programs, such as the Tooty Fruity Vegie project (Newell, Huddy, Adams, Miller, \& Holden, 2004), have been found to be effective (see also Baudinette, 2004; McConell \& Warren, 2004). 


\section{Children, peer relationships and bullying}

Communities must provide children with safe and supportive environments free from bullying (Rigby, 2009). While research suggests that children prefer not to talk to adults about bullying (Rigby, Cox, \& Black, 1997), it is important that children have regular opportunities to speak with professionals about their social relationships at school. Health and welfare practitioners should consider bullying as a possible cause of psychological and somatic symptoms in children (Forero et al., 1999). Further, it is important for children and their parents to understand that bullying occurs when children do not know how to cope with feelings such as depression, inferiority, anxiety, insecurity, fearfulness, and jealousy (Rigby, 2005b) or when they lack the confidence or skills necessary to engage in social situations (Cross et al., 2009; Rigby, 2005b). Children should be guided to understand that the targets of bullying behaviours have usually done nothing to encourage negative behaviour. Children who have been severely bullied require sustained intensive support to reinstate a sense of wellbeing, while children who have engaged in bullying must be supported to ensure they are not ostracised or excluded (Rigby, 2005a). Supportive social relationships and school connectedness are important for both children.

Strategies to reduce bullying are most successful if children play a key role in their implementation (Peterson \& Rigby, 1999). Strengths-based approaches to policy development in schools are important (see Smith, Pepler, \& Rigby, 2004; for a review of the National Safe Schools Framework see Ministerial Council on Education Employment Training and Youth Affairs [MCEETYA], 2003). Further, communities should be canvassed to identify children displaying bullying behaviours so that practitioners can guide parents towards appropriate interventions and behaviour management strategies. Programs should provide specialised training in bullying and violence prevention for adults involved with schools, such as teachers, parents, and other staff (Cross et al., 2009; for a review of antibullying programs in schools see Cross, 2008; Rigby, 2002; Rigby \& Thomas, 2002). Programs should focus on developing assertiveness - as opposed to aggressiveness, anger management, non-violent strategies, conflict resolution skills, self-esteem, and social skills (Cross et al., 2009; Rigby, 2003).The success of these interventions relies on linking children and their parents to other programs, such as those addressing domestic violence and child abuse (Cross et al., 2009).

\section{Children and abuse and neglect}

The direct and indirect costs associated with increasing notifications and out-of-home care placements will escalate if prevention programs, that reduce family and community vulnerability to child abuse and neglect, are not well resourced (O’Donnell et al., 2008). Universal health and education support services should be provided for all families, with secondary preventative support services offered to vulnerable families (O'Donnell et al., 2008; Rosenman \& Rodgers, 2004; Scott, 2006; for early intervention programs see Wise, da Silva, Webster, Sanson, 2005; for examples of three programs see Children Youth and Women's Health Service [CYWHS], 2005; Department of Community Services [DoCS], ND; Homel et al., 2006). Further, human service and health practitioners need to shift toward a preventative, as opposed to a crisis, led approach (Brigid, 2006; O’Donnell et al., 2008). As disadvantage is prevalent in particular neighbourhoods and geographical locations, community development approaches, which strengthen and build communities and address economic and social issues, are vital (FaHCSIA, 2009). 
Human service and health practitioners are advised to overcome the barriers which prevent interagency collaboration in child protection, including, but not limited to, poor communication, role clarity, confidentiality, interagency processes, unrealistic expectations, and insufficient knowledge about the legislative framework for each other's practice (Brigid, 2006; see the National Framework for Protecting Australia's Children 2009-2020 [FaHCSIA, 2009], for guidelines on interagency cooperation). Services should increase their capacity to respond to complex family needs across a diverse range of issues, ensure regular respite, and work towards the development and support of a family's informal support networks (Stanley, Tomison, \& Pocock, 2003). Organisations need to avoid adult-centric approaches and provide more holistic integrated services which includes assessing and monitoring children’s health and wellbeing (Brigid, 2006; O’Donnell et al., 2008).

\section{Key principles}

\section{Communities as conduits for change}

Communities are a central conduit for change for children and their families. The local community is where the needs and circumstances of children and families intersect (Chaskin, 2009). Children living in communities which experience poverty and disadvantage are more likely to have social, emotional, learning, and physical difficulties than children living in affluent communities, even when parental employment status, family income, mother's education, and other variables are controlled for (Edwards, 2006). Further, children's safety and wellbeing is enhanced in communities where people actively participate in community life (Chaskin, 2009; Edwards, 2006; Gardner, 2002; Sayers, 2008). Improvements in health and wellbeing indicators are inextricably linked to a perception of neighbourhood safety and a positive sense of belonging to a community (Gardner, 2002). Thus, community development activities, which promote a holistic approach to improving the health and wellbeing of children, are important. These activities should focus on leadership development and provide community members, including children, with opportunities to assume important roles within the community (Gardner, 2002). Organisations should seek to improve community access to needed goods, services, resources, and opportunities, and support the creation and reinforcement of community identity and advocacy (Edwards, 2006). They should focus on the broader organisational infrastructure of a community and foster links or specialised partnerships among organisations (Chaskin, 2009). Building a bridge between the community services and education sector-where schools are seen as the central hub for human services-ensures families are provided with timely support in a de-stigmatised, easily accessible context (Winkworth \& McArthur, 2005; see also Hayes \& Chodkiewicz, 2003; Lonsdale, 2009; MacGregor, 2006).

\section{Early intervention, prevention, and health promotion}

Prevention programs for young children can result in significant benefits, as they reduce later rates of social, behavioural, academic, and psychological problems. Programs that focus on health promotion and early intervention have resulted in positive long term outcomes, such as a reduction in anxiety and depression in children and improved health and nutrition (Graetz et al., 2008; Mobach \& Catlow, 2007; Neil \& Christensen, 2007). In addition, programs that have been trialled in the United States in high crime, low socioeconomic areas, and have employed teacher training, parenting programs, mentoring, and health promotion activities in schools, have resulted in reduced rates of risky sexual behaviour, pregnancy, and delinquency, as well as improved academic achievement for the children who participated in 
the program as opposed to those who did not (Lonczak, Abbott, Hawkins, Kosterman, \& Catalano, 2002; for other examples, see Barron-McKeagney, Woody, \& D'Souza, 2001; Hussey \& Flannery, 2007; Konu \& Rimpelä, 2002; Reynolds et al., 2007; Tierney, Grossman, \& Resch, 2000; Webster-Stratton, 2001). Such approaches enable families and communities to continue to manage issues before they become serious problems (Davies \& Taylor, 2005).

\section{Children's active participation in decision making}

There is growing international demand for promoting the participation of children in decision-making (see for example, Doel \& Best, 2008; Hart, 1997; James, 2007; Kirby, Lanyon, Cronin, \& Sinclair, 2003; United Nations Children's Fund [UNICEF], 2003) in a way which encourages and facilitates their ongoing and sustainable participation in the planning, implementation, and evaluation of services (Vicary, Tennant, Santa Maria, \& Wadley, 2005). However, it is generally teenagers, or those in their early twenties, who are invited to comment on programs and social policies, resulting in an absence of views and ideas from younger children (Vicary, Tennant, Garvie, \& Adupa, 2006). Providing platforms for children to express their concerns and offer solutions in relation to their health, wellbeing, and communities will help effectively address the issues confronting Australian children (Vicary et al., 2005). Using photovoice as a research method is one such way of involving children in service planning, as it is a non-intrusive, creative method of data collection, which caters to children's varying learning needs while identifying their attitudes, beliefs, views, hopes, dreams, and ideas for their community (Wang \& Burris, 1997). In addition, children's advisory groups which comprise 8-12 child members from a variety of schools allow children to voice their ideas directly to an organisation. The selected children work collaboratively with the organisation and become directly involved with projects and decisions affecting children by offering their experiences as child service users (Vicary et al., 2005). This participation should benefit children and increase their opportunity and capacity to make a difference.

\section{Implications for Practice}

This review of the literature indicates that human service, health, and social work practitioners working with Australian children aged six to twelve would benefit from considering a number of key issues in practice. As rates of child homelessness, child abuse and neglect, obesity, bullying, and mental illness increases, it is essential that practitioners and agencies engage in genuine collaboration with service users and community members to build strong healthy communities, where services are tailored to the wants and needs of those receiving them. Implementation of a children's advisory group, where children can express their concerns and offer their ideas, will help work towards genuine collaboration and ensure children's social inclusion in their communities. This approach engages children as service users, ensures organisational accountability, and promotes connections between schools, neighbourhoods, and communities.

Community organisations and primary schools should continue to build partnerships with one another. This will not only strengthen community services, but it will also help ensure that children who are identified as exhibiting problem behaviours, with poor attendance at school or health related concerns, are able to access professional support in non-intimidating and easily accessible settings. Further, the implementation of culturally appropriate programs which are coordinated in genuine partnerships with Indigenous representatives and target specific areas of concern for children and their communities may 
assist in addressing the disparity in health and economic status between Indigenous and nonIndigenous children. Preventative approaches, such as a healthy diet/healthy lifestyle program, that offer universal education and support to children, parents, and extended families are important as they can reduce later social, behavioural, academic, and psychological problems. Equally important, are secondary early intervention programs for addressing child abuse and neglect. Community development activities, which promote a holistic approach to improving the health and wellbeing of children, are also essential. Thus, a multi-layered approach is likely to result in improved child health.

\section{Areas for Further Research}

A number of gaps exist in the literature on models of practice with primary school aged children, particularly as it relates to disability, Indigenous children, and children from culturally and linguistically diverse backgrounds. Much of the research conducted in children's health and wellbeing focuses on the early years or adolescence. However, a greater focus on the primary school years, with recognition that it is a significant period in children's lives, is needed. Importantly, future research needs to hear children's voices and engage them in creating, implementing, and evaluating appropriate interventions and strategies to address the issues affecting them and their families. The following areas deserve particular mention:

- Australian research to date largely ignores the experiences of primary school aged children of culturally and linguistically diverse backgrounds and their families (for two exceptions, see Jianghong, D’Angiulli, \& Kendall, 2007; Kaur, 2009) and children who are refugees (for exceptions, see Lewig, Arney, \& Salveron, 2009; Mares \& Jureidini, 2004; Martin \& Hutchinson, 2005). Consequently, research should examine models for working with refugee school aged children and children from culturally and linguistically diverse backgrounds. Such research should employ a range of culturally sensitive and age appropriate qualitative research methods to hear children and their families' voices;

- while studies demonstrate that children with disabilities are more vulnerable to abuse and neglect, both in and outside the family environment, research with primary school aged children is limited. Appropriate interventions for working with children with disabilities and their families, to reduce their vulnerability, need to be developed and tested;

- empirically-based community interventions to address the health concerns affecting primary school aged Indigenous children are limited and approaches which consider both local and international research, combined with extensive Indigenous community engagement and genuine partnerships, are needed;

- while grandparents are increasingly involved in primary school children's lives, research to date has largely overlooked this area. As a result, more research is needed that considers the role grandparents play in raising children, the relationships grandparents have with their families, and the effects of grandparenting on grandparents' and children's lives; and

- there is a significant amount of literature on school bullying, yet there is little research regarding teachers', counsellors', and human service practitioners' views on addressing peer victimisation or research on community initiatives which respond to it. Further evaluation research is also needed to address the short and long term affects of cyberbullying with primary school aged children, along with the development, implementation, and evaluation of community-based initiatives to combat this type of bullying. 
Finally, while there is a significant amount of literature on practice interventions with children, much of this literature is not informed by empirical research, and that which is, comes predominantly out of the United States or United Kingdom. Research must identify concrete outcomes for funding to be made available to particular communities, as the usual top-down flow of resources from policy decisions will only be reversed if there is sound empirical evidence that social and economic investment will produce positive outcomes. Research must reveal what a community wants to enhance their quality of life and interventions must build on this and be evaluated as to their effectiveness. As a result, it is recommended that Australian practitioners and researchers engage in practice-based empirical research to underpin program development and that the findings from these studies are disseminated widely.

\section{Conclusion}

Numerous studies and reports confirm the need for an improved societal response to the needs of children and their families that recognises the interconnection between child, family, and community. Interventions which focus on children, families, and communities and seek to improve parenting skills, while strengthening family to community links can have important and sustainable benefits for primary school aged children. Although there is an identified need to continue the preventative work recommended by the literature during early childhood it is clear that the years from six to twelve are a unique time in children's lives as they prepare for young adulthood and experience major transitions to alternative environments. Consequently, it is vital that interventions continue to be provided to children during primary school to ensure every child receives support and is able to actively participate in society. Further, promoting stronger communities and structures to assist children and their families to develop trust and engage with each other through social and recreational activities remains a priority for service providers working with primary school aged children and their families, as it promotes social inclusion, children's health and wellbeing, and ensures that children have an opportunity to live in safer and increasingly supportive homes and communities.

\section{Note}

${ }^{1}$ 'Primary years' refers to Australian children in years K-6, who are usually between the ages of six and twelve

\section{References}

Aarons, N. M., \& Powell, M. B. (2003). Issues related to the interviewer's ability to elicit reports of abuse from children with an intellectual disability: A review. Current Issues in Criminal Justice, 14(3), 257-268.

Abbott, K. (2004). Return to the heart: Akeyulerre Apmere cultural health service. Aboriginal and Islander Health Worker Journal, 28(2), 4-5.

Ashton, J. (2004). Life after the shock! The impact on families of caring for young children with chronic illness. Australian Journal of Early Childhood, 29(1), 22-26.

Askell-Williams, H., Russell, A., Dix, K. L., Slee, P. T., Spears, B. A., Lawson, M. J., et al. (2008). Early challenges in evaluating the KidsMatter National Mental Health Promotion Initiative in Australian primary schools. International Journal of Mental Health Promotion, 10(2), 35-44. 
Australian Institute of Health and Family Welfare [AIHW] (2009). Picture of Australia's children Retrieved August 28, 2009, from http://www.aihw.gov.au

Australian Institute of Health and Welfare [AIHW] (2008). Making progress: The health, development and wellbeing of Australia's children and young people. Retrieved August 28, 2009, from http://www.aihw.gov.au

Australian Research Alliance for Children and Youth [ARACY] (2008). ARACY report card on the wellbeing of young Australians. Retrieved August 28, 2009, from http://www.aracy.org.au/index.cfm?pageName=report_card_overview

Barron-McKeagney, T., Woody, J. D., \& D'Souza, H. J. (2001). Mentoring at-risk Latino children and their parents: Impact on social skills and problem behaviors. Child and Adolescent Social Work Journal, 18(2), 119-136.

Batch, J. A., \& Baur, L. A. (2005). Management and prevention of obesity and its complications in children and adolescents. Medical Journal of Australia Practice Essential - Paediatrics, 182(3), 130-135.

Baudinette, S. (2004). High Five School Nutrition Project: Promoting healthy eating in primary schools. Health Education Australia Journal, 4(1), 48-50.

Bayer, J., Hiscock, H., Scalzo, K., Mathers, M., McDonald, M., Morris, A., et al. (2009). Systematic review of preventative interventions for children's mental health: What would work in Australian contexts? Australian and New Zealand Journal of Psychiatry, 43(8), 695-710.

Bayley, J., Wallace, L. M., \& Choudhry, K. (2009). Fathers and parenting programmes: Barriers and best practice. Community Practitioner, 82(4), 28-31.

Belsey, B. (2005). What is Cyberbullying? Retrieved March 14, 2010, from http://www.cyberbullying.org

Booth, M. L., King, L., A., Paginini, D. L., Wilkenfield, R. L., \& Booth, S., L (2009). Parents of school students on childhood overweight: The Weight of Opinion Study. Journal of Paediatrics and Child Health, 45(4), 194-198.

Booth, M. L., Oakley, A. D., Chey, T., Bauman, A. E., \& Macaskill, P. (2004). Epidemiology of physical activity participation among New South Wales school students. Australia and New Zealand Journal of Public Health, 26(4), 371-374.

Brandon, M., Schofield, G., \& Trinder, L. (1998). Social work with children. Basingstoke, UK: Macmillan.

Brigid, D. (2006). Child Protection. Research Matters, Apr-Oct, 25-31.

Burchill, M., Higgins, D., Ramsamy, L., \& Taylor, S. (2006). "Workin' together": Indigenous perspectives on community development. Family Matters, 2006(75), 50-59.

Catroppa, C., \& Anderson, V. (2008). Traumatic brain injury. Teacher Learning Network, 15(2), 12-13.

Chadwick, D., \& Kemp, C. (2002). Critical factors of successful transition to mainstream kindergarten for children with disabilities. Australian Journal of Special Education, 26(1/2), 48-66.

Chaskin, R. J. (2009). Building community capacity for children, youth and families. Children Australia, 34(1), 31-39.

Chenoweth, L. (2007). Life course approach to children with disabilities: What evidence for better practice? Paper presented at the Presentation to the Department of Child Safety, QLD, Australia.

Children Youth and Women's Health Service [CYWHS] (2005). Family home visiting service outline. Retrieved March 20, 2010, from http://www.cyh.com/library/CYWHS_FHV Service_Outline.pdf 
Coker, T. R., Eliott, M. N., Kanouse, D. E., Grunbaum, J. A., Gilliland, M. J., Tortolero, S. R., et al. (2009). Prevalence, characteristics and associated health and health care of family homelessness. American Journal of Public Health, 99(8), 1446-1452.

Cross, D. (2008). Friendly Schools and Families: An evidence based bullying reduction program. Retrieved October 21, 2009, from http://www.friendlyschools.com.au/ index.php

Cross, D., Shaw, T., Hearn, L., Epstein, M., Monks, H., Lester, L., et al. (2009). Australian Covert Bullying Prevalence Study (ACBPS.) Retrieved March 20, 2010, from http://www.deewr.gov.au

Daly, A. (2006). Social inclusion and exclusion among Australia's children: A review of the literature Discussion Paper No 62. Retrieved December 28, 2009, from National Centre for Social and Economic Modelling, www.natsem.canberra.edu.au

Daly, A., \& Smith, D. (2005). Indicators of risk to well-being of Australian Indigenous children. Australian Review of Public Affairs, 6(1), 39-57.

Davies, A., \& Taylor, C. (2005). Stronger families and communities strategy: Communities for Children Retrieved August 28, 2009, from Australian Government Department of Families, Housing, Community Services and Indigenous Affairs (FaHCSIA) website: http://raisingchildren.net.au/about_us/stronger_families.html

Davis, E., Sawyer, M., Lo, S. K., Priest, N., \& Wake, M. (2010). Socioeconomic risk factors for mental health problems in 4-5 year-old children: Australian population study. Academic Pediatrics, 10(1), 41-47.

Dell'Api, M., Rennick, J., E., \& Rosmus, C. (2007). Childhood chronic pain and health care professional interactions: Shaping the chronic pain experiences of children. Journal of Child Health Care, 11(4), 269-286.

Department of Community Services [DoCS] (ND). Brighter Futures program fact sheet. Retrieved 22 March, 2010, from http://www.community.nsw.gov.au/docswr/_assets/ main/documents/brighter_futures_fact.pdf

Department of Health and Ageing (2008). The 2007 National Children's Nutrition and Physical Activity Survey: Main findings. Retrieved October 20, 2009, from http://www.health.gov.au/internet/main/publishing.nsf/

Dockett, S. (2004). "Everyone was really happy to see me!" The importance of friendships in the return to school of children with chronic illness. Australian Journal of Early Childhood, 29(1), 27-32.

Dockett, S., \& Perry, B. (2006). Starting school: A handbook for early childhood educators. Sydney: Pademelon.

Dockett, S., \& Perry, B. (2007). Transitions to school: Perceptions, expectations and experiences. Sydney: University of New South Wales Press Ltd.

Dockett, S., \& Perry, B. (2009). Readiness for school: A relational construct. Australasian Journal of Early Childhood, 34(1), 20-26.

Doel, M., \& Best, L. (2008). Experiencing social work: Learning from service users. London: Sage.

Drysdale, A., \& Higgins, N. (2008). Supporting children with differences: The importance of partnerships. Educating Young Children: Learning and Teaching in the Early Childhood Years, 14(2), 16-17.

Edwards, B. (2006). Views of the village: Parents perceptions of their neighbourhoods. Family Matters, 74, 26-33.

Farrar, E., Goldfeld, S., \& Moore, T. (2007). School readiness. Melbourne: Australian Research Alliance for Children and Youth.

Fleming, M., \& Rickwood, D. (2004). Teens in cyberspace: Do they encounter friend or foe? Youth Studies Australia, 23(3), 46-52. 
Forero, R., McLellan, L., Rissel, C., \& Bauman, A. (1999). Bullying behaviour and psychosocial health among school students in New South Wales, Australia: Cross sectional survey. British Medical Journal, 319(7206), 344-348.

Gardner, F. (2002). Shared action: Stronger communities, safer children. Children Australia, 27(2), 23-28.

Gilmore, L. (1999). Pathways to prevention: Developmental and early intervention approaches to crime in Australia. Canberra, Australia: National Crime Prevention Authority, Attorney General's Department.

Graetz, B., Littlefield, L., Trinder, M., Dobia, B., Souter, M., Champion, C., et al. (2008). KidsMatter: A population health model to support student mental health and wellbeing in primary schools. International Journal of Mental Health Promotion, 10(4), 13-20.

Green, S., \& Baldry, E. (2008). Building Indigenous Australian social work. Australian Social Work, 61(4), 389-402.

Grist, J. (2009). Childhood sexual abuse. Australian Doctor, 29 May.

Hart, R. (1997). Children's participation: The theory and practice of involving young citizens in community development and environmental care. London: Earthscan.

Hayes, D., \& Chodkiewicz, A. (2003). School community links focused on learning in the middle years. Paper presented at the 3rd Australian Family and Community Strengths Conference, Building on Family and Community Strengths. Newcastle, NSW, Australia: University of Newcastle.

Higgins, D. (2003). The relationship of childhood family characteristics and current attachment styles to depression and depressive vulnerability. Australian Journal of Psychology, 55(1), 9-14.

Higgins, D., Bromfield, L., Higgins, J., \& Richardson, N. (2006). Protecting Indigenous children: Views of carers and young people on 'out-of-home care'. Family Matters, 2006(75), 42-49.

Hills, A. P., King, N. A., \& Armstrong, T. P. (2007). The contribution of physical activity and sedentary behaviours to the growth and development of children and adolescents: Implications for overweight and obesity. Sports Medicine, 37(6), 533-545.

Homel, R., Freiberg, K., Lamb, C., Leech, M., Batchelor, S., Carr, A., et al. (2006). The Pathways to Prevention project: Doing developmental prevention in a disadvantaged community. Trends and Issues in Crime and Criminal Justice, August 26(323), 1-6.

House of Representatives Standing Committee on Employment Education and Training (1994). Sticks and stones: Report on violence in Australian schools. Canberra: Parliament of the Commonwealth of Australia.

Hussey, D. L., \& Flannery, D. J. (2007). Implementing and evaluating school-based primary prevention programs and the importance of differential effects on outcomes. Journal of School Violence, 6(2), 117-136.

Ireys, H. T., Chernoff, R., DeVet, K. A., \& Kim, Y. (2001). Maternal outcomes of a randomized controlled trial of a community-based support program for families of children with chronic illness. Archives of Pediatrics \& Adolescent Medicine, 155(7), 771-777.

James, A. (2007). Giving voice to children's voices: Practices and problems, pitfalls and potentials. American Anthropologist, 109(2), 261-272.

Jianghong, L., D’Angiulli, A., \& Kendall, G. (2007). The early development index and children from culturally and linguistically diverse backgrounds. Early Years: An International Journal of Research and Development, 27(3), 221-235. 
Karim, K., Tischler, V., Gregory, P., \& Vostanis, P. (2006). Homeless children and parents: Short term mental health outcome. The International Journal of Social Psychiatry, 52(5), 447-458.

Kaur, J. (2009). Working with families from culturally and linguistically diverse communities in Queensland: An Australian exploratory study. Children Australia, 32(4), 17-24.

Kirby, P., Lanyon, C., Cronin, K., \& Sinclair, R. (2003). Building a culture of participation: Involving children and young people in policy, service planning, delivery and evaluation. London: National Children's Bureau and PK Research Consultancy.

Kolar, V. (2005). Home first: A longitudinal study of outcomes for families who have experienced homelessness - final report Retrieved January 24, 2010, from https://www.hanover.org.au/component/option,com_docman/task,cat_view/gid,33/

Konu, A., \& Rimpelä, M. (2002). Well-being in schools: A conceptual model. Health Promotion International, 17(1), 79-87.

Kratz, L., Uding, N., Trahms, C. M., Villareale, N., \& Kieckhefer, G. M. (2009). Managing childhood chronic illness: Parent perspectives and implications for parent-provider relationships. Families, Systems \& Health: The journal of collaborative family healthcare, 27(4), 303-313.

Larmar, S. (2008). The Early Impact Program: Strengthening child competencies. Australian Journal of Guidance and Counselling, 18(2), 128-140.

Larmar, S., \& Gatfield, T. (2005). Challenging behaviour in the regular classroom. International Journal of Diversity in Organisations, Communities and Nations, 5(1), 51-55.

Lewig, K., Arney, F., \& Salveron, M. (2009). The working with refugee families project. Adelaide: Department of Innovation, Industry, Science and Research with the South Australian Department for Families and Communities.

Libesman, T. (2004). Child welfare approaches for Indigenous communities: International perspectives. Child Abuse Prevention Issues, 20. Retrieved October 30, 2009, from http://www.aifs.gov.au/nch/pubs/issues/issues20/issues20.pdf

Lonczak, H. S., Abbott, R. D., Hawkins, J. D., Kosterman, R., \& Catalano, R. F. (2002). Effects of the Seattle Social Development Project on sexual behaviour, pregnancy, birth and sexually transmissible disease outcomes by age 21 years. Archives of Paediatrics and Adolescent Medicine, 156(5), 438-477.

Lonsdale, M. (2009). School-community partnership: A capital idea for school improvement. Teacher: The National Education Magazine, Aug, 54-57.

MacGregor, R. (2006). Engaging with parents, families and community: The why and how of effective and sustainable partnerships. Paper presented at the Mind Matters "Health Promotion \& Evaluation in School Settings" Seminar.

MacKean, G. L., Thurston, W. E., \& Scott, C. M. (2005). Bridging the divide between families and health professionals' perspectives on family-centered care. Health Expectations, 8(1), 74-85.

Mares, S., \& Jureidini, J. (2004). Psychiatric assessment of children and families in immigration detention - clinical, administrative and ethical issues. Australian and New Zealand Journal of Public Health, 28(6), 520-526.

Martin, F., \& Hutchinson, T. (2005). Mental health and human rights implications for unaccompanied minors seeking asylum in Australia. The Journal of Migration and Refugee Issues, 1(1), 1-24.

McCallum, D. (2009). Punishing welfare: The genealogies of child abuse. Griffith Law Review, 18(1), 14-30. 
McConell, K., \& Warren, C. (2004). Fruit 'n' Veg Eat It! A health promoting schools approach to increase fruit and vegetable consumption among primary school students. Health Education Australia, 4(1), 51-53.

McDonald, E. L., Bailie, R. S., Rombold, A. R., Morris, P. S., \& Paterson, B. A. (2008). Preventing growth faltering among Australian Indigenous children: Implications for policy and practice. Medical Journal of Australia, 188(Suppl 8), 84-86.

Ministerial Council on Education Employment Training and Youth Affairs [MCEETYA] (2003). National Safe Schools Framework Retrieved September 29, 2009, from http://www.mceetya.edu.au/verve/_resources/natsafeschools_file.pdf

Mobach, P., \& Catlow, L. (2007). CHAMPS - Children's Healthy Activities Mentoring Program for Schools. Paper presented at the 9th National Rural Health Conference.

Mockford, C., \& Barlow, J. (2004). Parenting programmes: Some unintended consequences. Primary Health Care Research and Development, 5(3), 219-227.

Moore, T., Noble-Car, D., \& McArthur, M. (2007). Finding their way home: Children's experience of homelessness. Canberra: Institute of Child Protection Studies, Australian Catholic University.

Must, A., \& Strauss, R. S. (1999). Risks and consequences of childhood and adolescent obesity. International Journal of Obesity, 23(Suppl 2), 2-11.

National Health and Medical Research Council [NHMRC] (2003). Dietary guidelines for children and adolescents in Australia. Retrieved October 20, 2009, from http://www.nhmrc.gov.au/_files_nhmrc/file/publications/synopses/n30

Neil, A. L., \& Christensen, H. (2007). Australian school based prevention and early intervention programs for anxiety and depression: A systematic review. Medical Journal of Australia, 186(6), 305-309.

Newell, S. A., Huddy, A. D., Adams, J. K., Miller, M., \& Holden, L. (2004). The Tooty Fruity Vegie project: Changing knowledge and attitudes about fruits and vegetables. Australian and New Zealand Journal of Public Health, 28(3), 288-295.

Nicholson, A. (2007). Child and youth homelessness: A nation's shame. Parity, 20(1), 6-8.

O'Brien, J. (2001). Planned respite care: Hope for families under pressure. Australian Journal of Social Issues, 36(1), 51-65.

O’Dea, J. A. (2008). Gender, ethnicity, culture and social class influences on childhood obesity among Australian school children: Implications for treatment, prevention and community education. Health and Social Care in the Community, 16(3), 282-290.

O’Donnell, M., Scott, D., \& Stanley, F. (2008). Child abuse and neglect: Is it time for a public health approach? Australian and New Zealand Journal of Public Health, 32(4), 325-331.

Okely, A. D., Booth, M. L., Hardy, L., Dobbins, T., \& Denney-Wilson, E. (2008). Changes in physical activity participation from 1985 to 2004 in a statewide survey of Australian adolescents. Archives of Paediatrics and Adolescent Medicin, 162(2), 179-180.

Peebles-Wilkins, W. (2006). Responding to children with chronic illness. Children \& Schools, 28(2), 67-68.

Peterson, L., \& Rigby, K. (1999). Countering bullying at an Australian secondary school with students as helpers. Journal of Adolescence, 22(4), 481-492.

Radcliffe, B., Ogden, C., Welsh, J., Carroll, S., Coyne, T., \& Craig, P. (2005). The Queensland school breakfast project: A health promoting schools approach. Nutrition and Dietetics, 62(1), 33-40.

Ray, L. D. (2002). Parenting and childhood chronicity: Making visible the invisible work. Journal of Pediatric Nursing, 17(6), 424-438. 
Reynolds, A. J., Temple, J. A., Ou, S.-R., Robertson, D. L., Mersky, J. P., Topitzes, J. W., et al. (2007). Effects of a school-based, early childhood intervention on adult health and well-being. Archives of Pediatrics \& Adolescent Medicine, 161(8), 730-739.

Rigby, K. (2002). A meta-evaluation of methods and approaches to reducing bullying in preschools and in early primary school in Australia. Canberra: Commonwealth Attorney General's Department.

Rigby, K. (2003). Stop the bullying: A handbook for schools (Rev. ed.). Melbourne: Australian Council for Social Research.

Rigby, K. (2005a). Bullying in schools and the National Safety School Framework. Teacher: The National Education Magazine, July, 20-22.

Rigby, K. (2005b). Why do some children bully at school? The contributions of negative attitudes towards victims and the perceived expectations of friends, parents and teachers. School Psychology International, 26(2), 147-163.

Rigby, K., Cox, I., \& Black, G. (1997). Cooperativeness and bully/victim problems among Australian school children. The Journal of Social Psychology, 137(3), 357-369.

Rigby, K., \& Johnson, B. (2006). Expressed readiness of Australian schoolchildren to act as bystanders in support of children being bullied. Educational Psychology, 26(3), 425440.

Rigby, K., \& Thomas, E. B. (2002). How Australian schools are responding to the problem of peer victimisation in schools: A report for the Criminology Research Council. Retrieved November 27, 2009, from http://www.criminologyresearchcouncil.gov.au/ reports200001-10.html

Rivers, A. (2009). A growing problem: Children with a mental illness or mental disorder. Health Voices Journal of the Consumer's Health Forum of Australia, 4, 8-9.

Robson, T., Ziviani, J., \& Spina, S. (2005). Personal experiences of families of children with a traumatic brain injury in the transition from hospital to home. Brain Impairment, 6(1), 45-55.

Rosenman, S., \& Rodgers, B. (2004). Childhood adversity in an Australian population. Social Psychiatry and Psychiatric Epidemiology, 39(9), 695-702.

Ryden, N. (2005). Family support in social work with children and families. In M. Jowitt \& S. O’Loughlin (Eds.), Social work with children and families. Exeter UK: Learning Matters Ltd.

Sanders, M. R. (1999). The Triple P-Positive parenting program: Towards an empirically validated multilevel parenting and family support strategy for the prevention of behavior and emotional problems in children. Clinical Child and Family Psychology Review, 2(2), 71-90.

Sangster, J., Eccleston, P., \& Porter, S. (2008). Improving children's physical activity during out-of-school hours care settings. Health Promotion Journal of Australia, 19(1), 1621.

Sanson, A., Nicholson, J., Ungerer, J., Zubrick, S., Wilson, K., Ainley, J., et al. (2002). Introducing the longitudinal study of Australian children LSAC discussion paper No1. Retrieved October 20, 2009, from http://www.aifs.gov.au/growingup/pubs/ discussionpaper1.pdf

Sawyer, M. G., Arney, F. M., Baghurst, P. A., Clark, J. J., Graetz, B. W., Kosky, R. J., et al. (2001). The mental health of young people in Australia. Canberra, Australia: Commonwealth Department of Health and Aged Care, Mental health and special programs branch.

Sayers, M. (2008). Building better communities for children. IMPACT, Spring, 12-14.

Scott, D. (1997). Beyond child rescue. Review: Institute of Public Affairs, 50(1), 11-13. 
Scott, D. (2006). Towards a public health model of child protection in Australia. Communities, Children and Families Australia, 1(1), 9-16.

Shiu, S. (2001). Issues in the education of students with chronic illness. International Journal of Disability, Development and Education, 48(3), 269-281.

Shiu, S. (2004). Maintaining the thread: Including young children with chronic illness in the primary classroom. Australian Journal of Early Childhood, 29(1), 33-38.

Sidebotham, P., \& Golding, J. (2001). Child maltreatment in the "Children of the Nineties": A longitudinal study of parental risk factors. Child Abuse and Neglect, 25(9), 11771200.

Silburn, S., Zubrick, S. R., Lawrences, D. M., Mitrou, F. G., De Maio, J. A., Blair, E., et al. (2006). The intergenerational effects of forced separation on the social and emotional wellbeing of Aboriginal children and young people. Family Matters, 2006(75), 10-17.

Smith, P., Mahdavi, J., Carvalho, M., \& Tippett, N. (2006). A report to the Anti-Bullying Alliance - An investigation into cyberbullying, its forms, awareness and impact, and the relationship between age and gender in cyberbullying. Retrieved October 30, 2009, from http://www.antibullyingalliance.org/ResearchandEvaluationTeam ResearchReport.htm

Smith, P., Pepler, D., \& Rigby, K. (2004). Bullying in schools: How successful can interventions be? Cambridge: Cambridge University Press.

Somerset, S., Ball, R., Flett, M., \& Geissman, R. (2005). School-based community gardens: Re-establishing healthy relationships with food. Journal of the Home Economics Institute of Australia, 12(2), 25-33.

St Leger, P., \& Campbell, L. (2008). Evaluation of a school-linked program for children with cancer. Health Education, 108(2), 117-129.

Stanley, J., Tomison, A. M., \& Pocock, J. (2003). Child abuse and neglect in Indigenous Australian communities. Child Abuse Prevention Issues, 19. Retrieved March 20, 2010, from www.aifs.gov.au/nch/pubs/issues/issues19/issues19.html

Stiefel, I., \& Renner, P. (2004). Beyond behaviour - The importance of communication and connection in parenting 'defiant' children: Pilot study and program. Australian and New Zealand Journal of Family Therapy, 25(2), 84-93.

Tierney, J. P., Grossman, J. B., \& Resch, N. L. (2000). Making a difference: An impact study of Big Brothers Big Sisters. Philadelphia: Public/Private Ventures.

Tilbury, C. (2009). The over-representation of Indigenous children in the Australian child welfare system. International Journal of Social Welfare, 18(1), 57-64.

Timperio, A., Salmon, J., \& Ball, K. (2004). Evidence based strategies to promote physical activity among children, adolescents and young adults: Review and update. Journal of Science and Medicine in Sport [supplement], 7(1), 20-29.

Uding, N., Kieckhefer, G. M., \& Trahms, C. M. (2009). Parent and community participation in program design. Clinical Nursing Research, 18(1), 68-79.

United Nations Children's Fund [UNICEF] (2003). The state of the world's children 2003. New York: United Nation's Children's Fund.

Vicary, D., Tennant, J., Garvie, T., \& Adupa, C. (2006). Can you hear me? The active engagement of Aboriginal children in the development of social policy by nonAboriginals. Children Australia, 31(1), 21-26.

Vicary, D., Tennant, J., Santa Maria, J., \& Wadley, S. (2005). Children as decision makers. Children Australia, 30(4), 4-10.

Vickers, M., Parris, M., \& Bailey, J. (2004). Working mothers of children with chronic illness: Narratives of working and caring. Australian Journal of Early Childhood, 29(1), 39-44. 
Walsh, P., Milford, C., \& Cain, L. (2003). More than just a roof: A study of family homelessness in Queensland Centre of Philanthropy and Non-profit Studies in conjunction with the Centre for Social Justice, Micah Projects Inc., Lifeline Community Care, Queensland Shelter, Social Action Office, Wesley Mission Brisbane, Brisbane City Council, and Queensland University of Technology. Retrieved 20 October, 2009, from http://cpns.bus.qut.edu.au

Wang, C., \& Burris, M. A. (1997). Photovoice: Concept, methodology, and use for participatory needs assessment. Health Education and Behavior, 24(3), 369-387.

Webster-Stratton, C. (2001). Nipping early risk factors in the bud: Preventing substance abuse, delinquency and violence in adolescence through interventions targeted at young children (0-8 years). Prevention Science, 2(3), 165-192.

Whitlock, E. P., Williams, S. B., Gold, R., Smith, P. R., \& Shipman, S. A. (2005). Screening and interventions for childhood overweight: A summary of evidence for the US Preventative Services Taskforce. Paediatrics, 116(1), 125-144.

Winkworth, G., \& McArthur, M. (2005). Breaking into schools: Establishing high quality human services in educational contexts. Children Australia, 30(1), 19-26.

Wise, S., da Silva, L., Webster, E., \& Sanson, A. (2005). The efficacy of early childhood interventions: Australian Institute of Family Studies.

Wolak, J., Finkelhor, D., Mitchell, K. J., \& Ybarra, M. L. (2008). Online "Predators" and their victims - Myths, realities, and implications for prevention and treatment. American Psychologist, 63(2), 111-128.

Woodbridge, S. (2008). Sustaining familes in the 21st century: The role of grandparents. The International Journal of Environmental, Cultural, Economic and Social Sustainability, 4(2), 61-68.

Woodward, L. J., \& Fergusson, D. M. (2000). Childhood peer relationship problems and later risks of educational under-achievement and unemployment. Journal of Child Psychology and Psychiatry, 41(2), 191-201.

Wright-Howie, D. (2007). Children experiencing homelessness: A consistent reality requiring distinct policy attention. Parity, 20(5), 15-16.

\section{Biographical notes}

Gabrielle Le Bon has worked in community services and mental health for 12 years and is currently studying toward her Master of Social Work (Qualifying) at Griffith University. As part of her role as a senior research assistant, Gabrielle is investigating local primary school aged children's likes and dislikes about their neighbourhoods and communities using photovoice as the primary method. Her research and practice interests include health and the arts, feminism, and community and social activism.

Jennifer Boddy joined the School of Human Services and Social Work at Griffith University in 2009 as a lecturer. Her PhD research, which she completed in 2008, involved the design, implementation and evaluation of a mentoring program for women from socioeconomically disadvantaged communities. Her research and practice interests include community capacity building, social inclusion, feminism, and social activism. 